\title{
REACTIONS OF SUGARS AND POLYATOMIC ALCOHOLS IN BORIC ACID AND BORATE SOLUTIONS, WITH SOME ANALYTICAL APPLICATIONS.
}

\author{
Br G. VAN B. GILMOUR, B.So. (Lond.), A.R.C.So.I., A.I.C.
}

THE property which boric acid solutions exhibit of becoming more acidic on addition of certain polyatomic alcohols and sugars was first pointed out by Klein in 1878 (Bull. Soc. Chim., 29, 195). The explanation of such reactions was that combinations take place with the production of stronger acids. The subject has since been the source of a large amount of research, which has added very considerably to our knowledge of this type of reaction. It has been found that not only polyatomic alcohols and sugars form such combinations, but also that a large class of hydroxy compounds reacts similariy. The tendency of forming strong or weak complexes depends very largely on the position of the hydroxy groups, and Böseken has stated (Rec. Trav. Chim., 1915, 34, 96-113) that when these groups are in the same plane and on the same side as the two carbon atoms to which they are bound, the position is favourable for condensation.

Early investigators stated that the polysaccharides failed to give positive reactions. Thomson ( $J$. Soc. Chem. Ind., 1893, 12, 432-433) obtained a positive reaction with cane-sugar, and the author has shown that lactose and maltose react in like manner. Thomson (loc. cit.) applied the reaction to a volumetric method of estimating boric acid. He found that in the presence of glycerol boric acid could be titrated to the compound $\mathrm{NaBO}_{2}$. He tried to replace glycerol by dextrose and cane-sugar, with unsuccessful results; in these cases the indicator showed up before sufficient alkali was added to convert the acid into metaborate. Vedam (J. Pharm. Chim., 1898 [vi.], 8, 109-111) used mannitol in this titration; he considered that a sharper endpoint was obtained with mannitol than with glycerol.

The increase in electrical conductivity imparted to boric acid solutions by the addition of polyhydroxy bodies is a measure of the stability of the compounds formed. The addition of mannitol has a very marked positive effect compared with glycerol, and this is reflected in the proportional parts of mannitol to glycerol required in the titration of a given quantity of boric acid; twelve times more of the latter than of the former must be present.

The author has been able to titrate boric acid successfully in the presence of lævulose, dextrose, and cane-sugar. Other very soluble sugars will probably act like these, but it was found impossible to carry out the titration with lactose. Weak combinations require a large excess of the hydroxy compound, otherwise the complex is hydrolysed before the proper end-point is reached. At 3 per cent. concentration dextrose, cane-sugar, lactose, and maltose have practically no influence on the acidity of boric acid compared with lævulose, which was found at this concentration to have a very powerful positive reaction, the effect on the acidity being of the same order as that of mannitol.

Ageno and Valla (Gazetta, 1913, 43, 11, 163-174) from solubility measurements considered that boric acid and mannitol unite in equimolecular proportions. More 
recently Gran and Nossoivitsch (Monatsch., 1916, 37, 409-423) have prepared salts of complex bodies formed by the union of boric acid with mannitol, sorbitol, and dulcitol. There can be no doubt that similar compoundsjare produced by combina. tion with the sugars. The author has prepared the sodium derivative of a complex formed from lævulose and boric acid by a method similar to that used by Grun and Nossoivitsch (loc. cit.). The constitution of this compound is being determined.

\section{Reactions between Mannitol, Boric adid, and Caustio Soda.}

An explanation of these reactions, which agrees with the observations of Kahlenberg and Schreiner (Zeitsch. physikal Chem., 1896, 20, 547-568) and of Magnanini (Gaz. Chim., 428-440, 21, 134-145), is as follows:

On addition of considerable excess of mannitol to a solution of boric aoid, a union takes place in equimolecular quantities (Ageno and Valla, loc. cit.) to produce mannito-boric acid, $\mathrm{C}_{6} \mathrm{H}_{12} \mathrm{O}_{6}$. $\mathrm{BOH}$. When caustic soda is added to this, the sodium salt is formed, which is stable in acid solution, but in neutral or alkaline solution in the presence of mannitol it is readily hydrolysed into sodium metaborate and mannitol. The former is not stable in solution, and when liberated it immediately satisfies its residual valenoy by attracting whole mannitol molecules to form with them compounds like $\mathrm{NaBO}_{2} \cdot 3 \mathrm{O}_{6} \mathrm{H}_{14} \mathrm{O}_{6}$. In the volumetric estimation of boric acid the author has found that the minimum quantity of mannitol or løvulose required to enable the acid to be titrated to the metaborate is approximately three molecules of either for one of the acid. These observations, together with the knowledge that the compound trimannitol sodium metaborate, $\mathrm{NaBO}_{2}, 3 \mathrm{C}_{6} \mathrm{H}_{14} \mathrm{O}_{6}, 5 \mathrm{H}_{2} \mathrm{O}$, had been prepared (Grun and Nossoivitsoh, loc. cit.), led to the above explanation being put forward as to what happens when boric acid solutions are titrated in the presence of mannitol. Fructose seems to act exactly like mannitol, and, indeed, the type of reactions described might be considered general for polyhydroxy compounds that permit of the volumetric estimation of boric acid, the final state being one molecule of metaborate combined with one or more of the compound.

The acidity imparted to borax solutions by the addition of mannitol is due either to free boric acid, or to a mixture of boric acid and mannito-boric acid, or to mannito-boric acid alone, the final stage depending on the quantity of mannitol added. The following equations will illustrate this, in which the effect of adding two, three, and four molecular proportions of mannitol to one of borax is shown:

$$
\begin{aligned}
& \mathrm{Na}_{2} \mathrm{~B}_{4} \mathrm{O}_{7}+7 \mathrm{H}_{2} \mathrm{O}=2 \mathrm{NaOH}+4 \mathrm{H}_{3} \mathrm{BO}_{3} \text { (Kahlenberg and Schreiner, loc. cit.). } \\
& 2 \mathrm{C}_{6} \mathrm{H}_{14} \mathrm{O}_{6}+2 \mathrm{NaOH}+4 \mathrm{H}_{8} \mathrm{BO}_{3}=2 \mathrm{C}_{6} \mathrm{H}_{12} \mathrm{O}_{6} \cdot \mathrm{BONa}+2 \mathrm{H}_{3} \mathrm{BO}_{3}+2 \mathrm{H}_{2} \mathrm{O} . \\
& 3 \mathrm{C}_{6} \mathrm{H}_{14} \mathrm{O}_{6}+2 \mathrm{NaOH}+4 \mathrm{H}_{3} \mathrm{BO}_{3}=2 \mathrm{C}_{6} \mathrm{H}_{12} \mathrm{O}_{6} \mathrm{BONa}+\mathrm{C}_{6} \mathrm{H}_{12} \mathrm{O}_{6} \mathrm{BOH}+\mathrm{H}_{8} \mathrm{BO}_{3}+3 \mathrm{H}_{2} \mathrm{O} . \\
& 4 \mathrm{C}_{6} \mathrm{H}_{14} \mathrm{O}_{6}+2 \mathrm{NaOH}+4 \mathrm{H}_{3} \mathrm{BO}_{8}=2 \mathrm{C}_{6} \mathrm{H}_{12} \mathrm{O}_{6} \mathrm{BONa}+2 \mathrm{C}_{6} \mathrm{H}_{12} \mathrm{O}_{6} \mathrm{BOH}+4 \mathrm{H}_{2} \mathrm{O} .
\end{aligned}
$$

\section{Borio AOID IN MILK.}

Farrington (J. Amer. Chem. Soc., 1896, 18, 847) found that when boric acid is added to fresh milk its acidity to phenolphthalein, is about four times as great as that of an aqueous solution containing the same quantity of the acid. Farlier in 
this peper it has been pointed out that lactose combined with borio acid to produce a stronger acid, and if the table showing the effect of different quantities of lactose on the acidity of a solution of boric acid given in the experimental portion of the paper is consulted, it will be seen that the production of lacto-boric acid satisfactorily explains Farrington's observation.

Oatalytic Action of Boric Acid.-Luowenthal and Lenssen (J. prac. Chem., 1862, 85, 401) stated that boric acid retards the catalytic action of hydrochloric acid in the inversion of cane sugar. Their results were disputed by Arafura (Mem. Coll. Sci. Eng., Kyoto, 1909-10, 2, 229-236), who clearly showed the reverse to be the case. Arafura found that when the concentration of the hydrochloric acid is kept constant the accelerating effect of boric acid increases with its concentration, whereas the influence of boric acid on the catalytic action of hydrochloric acid is practically independent of the concentration of the latter aoid.

It is easy to explain these observations of Arafura now that it is known that lævulose forms a strong lævaloso-boric acid. What actually happens is that the boric acid assists the inversion in two ways: firstly, it removes one of the products of inversion in the sense that its properties are altered; and, secondly, it forms a strong acid that assists the action of the hydrochloric acid.

Analytical Applications.-Løvulose can be used in the volumetric estimation of boric acid. On account of the high price of the pure sugar, its use would be prohibitive in such estimations. Invert sugar, on the other hand, is cheaply prepared, and is an excellent substitute. This is strongly recommended as a reagent to replace glycerol or mannitol. To titrate a given amount of boric acid, the minimum quantity of invert sugar required is about double the minimum of fructose.

The observation that cane-sugar and dextrose have practically no effect when present with lærulose, even in considerable excess, has led the author to attempt a method of estimating lævulose by finding to what point a known volume of standard boric acid can be titrated on the addition of a weighed quantity of the lavulose mixture, the acid's equivalent of lævulose being already determined. In the experimental portion of the paper a series of results is given; these are very encouraging, and it is thought that if the method is carefully standardised fairly accurate estimations can be made. A method such as this would be useful in the analysis of cane-syrup and honey, where the reducing sugar is practically all invert. The lævulose estimated in this way after the reducing sugar has been determined should give a figure approximately half that of the latter.

A method for estimating lavulose based on the measurement of the increase in electrical conductivity of boric acid solutions after the addition of lævulose might possibly give more accurate results than those obtained by the above titration method.

Suggested Use of Lavuloso-Boric Acid.-In medicine there are a number of wellknown preparations in which the antiseptic properties of borax or boric acid are increased by means of glycerol. There is one preparation, "Mel Boracis," made from borax, glycerol, and honey, where the action of the honey has not been understood. The active principle in this preparation is lavuloso-boric acid, $\mathrm{C}_{6} \mathrm{H}_{10} \mathrm{O}_{6} \mathrm{BOH}$. This acid is very much more powerful than the corresponding glyceryl compound, and it is here suggested that invert sugar-syrup might be used more successfully as 


\section{GILMOUR: REACTIONS OF SUGARS AND POLYATOMIO ALCOHOLS}

a basis for this type of preparation than glycerol, and, further, for the sake of economy, it should replace honey in "Mel Boracis."

Experimental.-Tables I. to X. show the effect of different amounts of polyatomic alcohols and sugars on the end-points in the titration of deci-molecular solutions of boric acid with deci-normal soda, using phenolphthalein as indicator, the end-point in each osse being the first distinet pink coloration. When the alcohol or sugar was not neutral the acidity was determined and allowed for.

TABLI I.-GIYYCEROL.

\begin{tabular}{|c|c|c|}
\hline $\begin{array}{c}\text { C.c. } \frac{\mathrm{x}}{\mathrm{H}_{3}} \mathrm{BO}_{3} \\
\mathrm{BO}\end{array}$ & Grms. of Glycerol. & C.c. $\frac{\mathrm{N}}{10} \mathrm{NaOH}$. \\
\hline $\begin{array}{c}10 \cdot 0 \\
" 1 \\
" 1 \\
" \\
" \\
" \\
"\end{array}$ & $\begin{array}{l}\text { Nil } \\
2 \cdot 0 \\
3 \cdot 0 \\
4.0 \\
5 \cdot 0 \\
6 \cdot 0 \\
7 \cdot 0 \\
8.0\end{array}$ & $\begin{array}{r}0.6 \\
7.8 \\
9.0 \\
9.4 \\
9.6 \\
9.7 \\
9.8 \\
10.0\end{array}$ \\
\hline
\end{tabular}

Tabie II.-Mannitos.

\begin{tabular}{|c|c|c|c|}
\hline $\begin{array}{l}\text { C.c. } \frac{1}{10} \text { Molecule } \\
\frac{\mathrm{H}_{3} \mathrm{BO}_{4} \text {. }}{}\end{array}$ & C.c. of Water. & $\begin{array}{l}\text { Grm. of } \\
\text { Mannitol. }\end{array}$ & C.o. $\frac{\mathrm{N}}{20} \mathrm{NaOH}$. \\
\hline $\begin{array}{c}10 \\
" \\
" \\
" \\
" \\
" \\
" \\
" \\
" \\
" \\
" \\
" \\
" \\
" \\
" \\
" \\
"\end{array}$ & 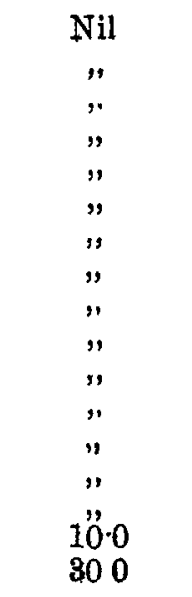 & $\begin{array}{l}\text { Nil } \\
0.05 \\
0.10 \\
0.15 \\
0.20 \\
0.25 \\
0.30 \\
0.35 \\
0.40 \\
0.45 \\
0.50 \\
0.55 \\
0.60 \\
0.65 \\
0.30 \\
" \prime \\
" \prime\end{array}$ & $\begin{array}{r}0.6 \\
2.0 \\
3.6 \\
4.9 \\
6.0 \\
7 \cdot 1 \\
7.9 \\
8.6 \\
9.0 \\
9.2 \\
9.5 \\
9.8 \\
9.9 \\
10.0 \\
4.9 \\
4.7 \\
4.2\end{array}$ \\
\hline
\end{tabular}


IN BORIC ACID AND BORATE BOLUTHONS

TaBLe III.-LamvLose.

\begin{tabular}{|c|c|c|}
\hline C.c. $\frac{1}{16}$ Molecule $\mathrm{H}_{3} \mathrm{BO}_{8}$. & Grm. of Lærulose. & O.c. $\frac{\mathrm{N}}{20} \mathrm{NaOH}$. \\
\hline $\begin{array}{c}10 \cdot 0 \\
" \\
" \\
" \\
" \\
" \\
" \\
" \\
" \\
" \\
" \\
" \\
"\end{array}$ & $\begin{array}{l}\text { Nil } \\
0.05 \\
0.10 \\
0.15 \\
0.20 \\
0.25 \\
0.30 \\
0.35 \\
0.40 \\
0.45 \\
0.50 \\
0.55 \\
0.60 \\
0.70\end{array}$ & $\begin{array}{r}0.6 \\
2.0 \\
3.6 \\
4.6 \\
6.0 \\
6.7 \\
7.6 \\
8.1 \\
8.6 \\
9.0 \\
9.3 \\
9.5 \\
9.8 \\
10.0\end{array}$ \\
\hline
\end{tabular}

The sugar used above contained approximately 90 per cent. of lavulose, so that the figures in the centre column are 10 per cent, too high.

TABLA IV.-Dixtrosf.

\begin{tabular}{|c|c|c|c|}
\hline O.c. ${\stackrel{\text { Io }}{\mathrm{H}_{3}}}_{3}^{\mathrm{B}} \mathrm{BO}_{3}$. & O.c. of Water. & $\begin{array}{l}\text { Grms. of } \\
\text { Dextrose. }\end{array}$ & C.e. $\frac{\mathrm{N}}{\mathrm{I}} \mathrm{NaOH}$. \\
\hline $\begin{array}{l}5 \cdot 0 \\
" 1 \\
" 1 \\
", \\
" 1 \\
"\end{array}$ & $\begin{array}{c}10 \cdot 0 \\
" \\
" \\
" \\
" \\
" \\
"\end{array}$ & $\begin{array}{l}\mathrm{Nil} \\
0 \cdot 3 \\
1 \cdot 0 \\
3 \cdot 0 \\
5 \cdot 0 \\
6 \cdot 0 \\
7 \cdot 2\end{array}$ & $\begin{array}{l}0.3 \\
0.9 \\
2 \cdot 8 \\
4.0 \\
4 \cdot 6 \\
4.9 \\
5 \cdot 0\end{array}$ \\
\hline
\end{tabular}

TABLE V.-Cani-SUGar.

\begin{tabular}{|c|c|c|c|}
\hline 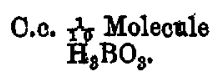 & O.c. of Water. & $\begin{array}{c}\text { Grms. of } \\
\text { Oame-Sugar. }\end{array}$ & C.e. $\frac{N}{10} \mathrm{NaOH}$. \\
\hline $\begin{array}{l}\mathbf{5} \cdot 0 \\
" \\
" \\
" \\
" \\
" \\
"\end{array}$ & $\begin{array}{c}10 \cdot 0 \\
" \\
" \\
" \\
" \\
1 " \\
15 \cdot 0\end{array}$ & $\begin{array}{r}\text { Nil } \\
0.3 \\
1.0 \\
10.0 \\
15.0 \\
25.0 \\
35.0 \\
43.0\end{array}$ & $\begin{array}{l}0.3 \\
0.3 \\
0.6 \\
3 \cdot 4 \\
4.0 \\
4.6 \\
5.0 \\
5.0\end{array}$ \\
\hline
\end{tabular}


TabLe VI.-Lactose.

\begin{tabular}{|c|c|c|}
\hline C.c. 㺼 Molecule $\mathrm{H}_{3} \mathrm{BO}_{3}$ & C.c. of Lactose. & C.c. $\frac{\mathrm{N}}{10} \mathrm{NaOH}$ \\
\hline $\begin{array}{l}5 \cdot 0 \\
" \\
" \\
" \\
" \\
" \\
" \\
"\end{array}$ & $\begin{array}{r}\mathrm{Nil} \\
5.0 \\
10.0 \\
15.0 \\
25.0 \\
50 \cdot 0 \\
80.0 \\
1400 \\
280.0 \\
450.0\end{array}$ & $\begin{array}{l}0 \cdot 3 \\
1 \cdot 7 \\
2 \cdot 2 \\
2 \cdot 6 \\
3 \cdot 0 \\
3 \cdot 5 \\
3 \cdot 8 \\
4 \cdot 1 \\
4 \cdot 4 \\
4 \cdot 0\end{array}$ \\
\hline
\end{tabular}

Solution used contained 18 grms. of sugar in 100 c.c. of water.

TABLE VII.-MaLtose.

\begin{tabular}{c|c|c|c}
\hline C.c. $\frac{1}{10} \mathrm{Molecule}_{\mathrm{H}_{3} \mathrm{BO}_{3}}$ & O.c. of Water. & $\begin{array}{c}\text { Grms. of } \\
\text { Maltose. }\end{array}$ & O.c. $\frac{\mathrm{N}}{\mathrm{I}} \mathrm{NaOH}$. \\
\hline 5.0 & $\mathrm{Nil}$ & $\mathrm{Nil}$ & 0.3 \\
$" \prime$ & 10.0 & 1.0 & 1.6 \\
$"$ & 50.0 & 10.0 & 3.1 \\
\hline
\end{tabular}

More titrations with maltose were not carried out because, as the concentration increased, the solution became so dark in colour that the end-point could not easily be determined.

Table VIII.-Mannitol and Dextrose.

\begin{tabular}{c|c|c|c}
\hline O.c. $\frac{1}{10} \mathrm{Molecule}_{3}$ & $\begin{array}{c}\text { Grm. of } \\
\mathrm{H}_{3} \mathrm{BO}_{3^{*}}\end{array}$ & $\begin{array}{c}\text { Grm. of } \\
\text { Mermitol. }\end{array}$ & O.c. $\frac{\mathrm{N}}{10} \mathrm{NaOH}$ \\
\hline 10.0 & 0.1 & 0.1 & 4.0 \\
$"$ & 0.2 & 0.2 & 6.4 \\
$"$ & 0.3 & 0.3 & 8.2 \\
$"$ & 0.5 & 0.5 & 9.6 \\
\hline
\end{tabular}


IN BORIC ACID AND BORATE SOLUTIONS

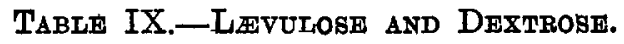

\begin{tabular}{|c|c|c|c|}
\hline $\begin{array}{l}\text { O.c. 章 Molecule } \\
{ }_{\mathrm{H}_{3}} \mathrm{BO}_{3} \text {. }\end{array}$ & $\begin{array}{c}\text { Grm. of } \\
\text { Lævilose. }\end{array}$ & $\begin{array}{c}\text { Grm. of } \\
\text { Dextrose. }\end{array}$ & O.c. $\mathrm{NaOH}$. \\
\hline $\begin{array}{c}10 \cdot 0 \\
" \\
" \\
"\end{array}$ & $\begin{array}{l}0.1 \\
0.2 \\
0.3 \\
0.5\end{array}$ & $\begin{array}{l}0.1 \\
0.2 \\
0.3 \\
0.5\end{array}$ & $\begin{array}{l}4 \cdot 0 \\
6 \cdot 5 \\
8 \cdot 1 \\
9 \cdot 6\end{array}$ \\
\hline
\end{tabular}

The lævulose weights are 10 per cent. too high for the same reason as explained in Table III.

Table X.-Mannitol, Dextrose, and Cane-Sugar.

\begin{tabular}{c|c|c|c|c}
\hline $\begin{array}{c}\text { O.c. } \frac{1}{10} \mathrm{Molecule}_{3} \\
\mathrm{H}_{3} \mathrm{BO}_{3^{\circ}}\end{array}$ & $\begin{array}{c}\text { Grm. of } \\
\text { Mannitol. }\end{array}$ & $\begin{array}{c}\text { Grm. of } \\
\text { Dextrose. }\end{array}$ & $\begin{array}{c}\text { Grm. of } \\
\text { Cane+Sugar. }\end{array}$ & O.c. $\frac{\mathrm{N}}{10} \mathrm{NaOH}$. \\
\hline 10.0 & 0.1 & 0.1 & 0.1 & 4.0 \\
$" \prime$ & 0.2 & 0.2 & 0.2 & 6.5 \\
$"$ & 0.3 & 0.3 & 0.3 & $8 \cdot 2$ \\
$"$ & 0.5 & 0.5 & 0.5 & 9.7 \\
\hline
\end{tabular}

Preparation of Invert Sugar Reagent.

A satisfactory and rapid laboratory method is as follows:

Twenty-five grms. of cane-sugar are heated with 10 c.c. of water in a conical flask until completely dissolved; the solution is boiled for a few minutes. Add 1 c.c. of $\frac{N}{2} \mathrm{HCl}$ to the hot solution, and shake well without reheating. Now dilute, cool, and add 1 c.c. of $\frac{\mathrm{N}}{2} \mathrm{NaOH}$, making the volume up to 50 c.c. This reagent is neutral and practically colourless, and 3 c.c. will enable 10 c.c. of $\frac{1}{10}$ molecule boric acid to be titrated. The minimum quantities of glycerol, mannitol, and invert sugar required to titrate $1 \mathrm{grm}$. of boric acid are respectively $128 \cdot 0,11 \cdot 2$; and $22 \cdot 4 \mathrm{grms}$.

\section{Estimation of Limpdiose.}

It was first thought that lævulose might be estimated by determining the volume of a solution of the sugar that must be added to a known volume of an equi-molecular solution of caustic soda and borio acid containing phenolphthalein, so as to just discharge the colour. This proved unsatisfactory; the colour faded fairly regularly until near the end-point, when the last trace of pink persisted to remain even after considerable additions of the sugar solution. The quantity of lævulose required to discharge the colour by this method is greater than that necessary to enable the same amount of boric acid to be titrated directly. The method finally arrived at was based on the results of the titrations shown in Tables III. and IX. It is carried out as follows : 


\section{REACTIONS OF SUGARS AND POLYATOMIO ALCOHOLS IN BORIC ACID}

To a flask containing a weighed amount of the lavulose mixture are added 10 c.c. of a $\frac{1}{10}$ molecular solution of $\mathrm{H}_{3} \mathrm{BO}_{3}$ and 0.5 c.c. of 1 per cent. phenolphthalein. This is titrated to the first distinct pink by the ddition of $\frac{\mathrm{N}}{10} \mathrm{NaOH}$; on standing a little while the pink fades, but the first end-point is taken. The lævulose equivalent of the soda added is read off from table of equivalents already calculated.

Table XI. below gives lævalose equivalents when mixtures such as syrup or honey are being analysed. In this table allowances have been made for the effect of other sugars present on the end-point. For volumes of $\frac{N}{10} \mathrm{NaOH}$ intermediate to any two adjacent figures in the table it can be assumed that the lævulose equivalents increase proportionately.

\begin{tabular}{ccc}
\multicolumn{3}{c}{ TABLE XI. } \\
Grm. of Lnevulose & equivalent to & c.c. $\frac{N}{10} \mathrm{NaOH}$. \\
0.22 & & $7 \cdot 2$ \\
0.27 & & $8 \cdot 1$ \\
0.31 & & $8 \cdot 5$ \\
0.36 & & $8 \cdot 9$ \\
0.40 & & $9 \cdot 2$ \\
0.45 & & $9 \cdot 5$
\end{tabular}

It is considered that best results are obtained whon the $\frac{\mathrm{N}}{10} \mathrm{NaOH}$ readings lie between 6.5 and 9.5. A preliminary titration will indicate what quantities of the lævulose mixture are necessary to give readings between these limits.

Examples :

A Sample of cane-syrup containing 46.0 per cent. invert sugar.

B honey $75 \cdot 9$ 3 2s

\begin{tabular}{|c|c|c|c|c|c|}
\hline Mixture. & $\begin{array}{l}\text { Grms. of } \\
\text { Mixture. }\end{array}$ & C.c. $\frac{1}{10} \frac{\text { Molecule }}{\mathrm{H}_{8} \mathrm{BO}_{3} \text {. }}$ & $\begin{array}{l}\text { O.o. } \frac{\mathrm{N}}{\mathrm{I0}} \mathrm{NaOH} \\
\text { for Blank. }\end{array}$ & 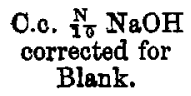 & $\begin{array}{l}\text { Per Cent. } \\
\text { Lærulose. }\end{array}$ \\
\hline $\begin{array}{l}\mathbf{A} \\
\ddot{B} \\
",\end{array}$ & $\begin{array}{l}1.2 \\
2.0 \\
0.6 \\
0.9\end{array}$ & $\begin{array}{c}10.0 \\
" 1 \\
" 1\end{array}$ & $\begin{array}{l}0.4 \\
0.6 \\
0.1 \\
0.2\end{array}$ & $\begin{array}{l}8.2 \\
9.5 \\
7.3 \\
8.9\end{array}$ & $\begin{array}{l}23 \cdot 3 \\
22 \cdot 5 \\
38 \cdot 4 \\
40 \cdot 0\end{array}$ \\
\hline
\end{tabular}

The percentage error in these estimations is of the order of 10 per cent., and is mainly due to the difficulty in determining the end-point.

Mappole Laboratory,

SoUthaLl. 